\title{
Energy saving potential and repercussions on indoor air quality of demand controlled residential ventilation strategies.
}

\author{
J. Laverge ${ }^{1}$, N. Van Den Bossche ${ }^{1}$, N. Heijmans ${ }^{2}$ \& A. Janssens ${ }^{1}$ \\ ${ }^{1}$ Ghent University, Department of Architecture and Urban Planning, \\ Jozef Plateaustraat 22, Gent, Belgium \\ ${ }^{2}$ Belgian Building Research Institute, \\ Avenue P. Holoffe 21, Limelette, Belgium
}

Corresponding Author:

tel $+3292643749 /$ fax +3292644185

email jelle.laverge@ugent.be

KEYWORDS: Demand control; Residential ventilation; Monte-Carlo; IAQ

ABSTRACT: Ventilation is ambiguously related to the energy saving rationale originating from the mitigation of global warming, the reaching of peak oil or health concerns related to fossil fuel burning. Since it makes up for about half of the energy consumption in well insulated buildings, it is an attractive target for energy saving measures. However, simply reducing ventilation rates has unwanted repercussions on the indoor air quality. Two main strategies have been developed to reconcile these seemingly opposing interests: heat recovery and demand control ventilation. This paper focuses on the energy saving potential of demand controlled mechanical exhaust ventilation in residences and on the influence such systems may have on the indoor air quality to which the occupants of the dwellings are exposed. The conclusions are based on simulations done with a multi-zone airflow model of a detached house that is statistically representative for the average Belgian dwelling. Four approaches to demand based control are tested and reported. Within the paper exposure to carbon dioxide and to a tracer gas are used as indicators for indoor air quality. Both energy demand and exposures are reported and compared to the results for a standard, building code compliant, exhaust system, operating at continuous flow rates. The sensitivity of the control strategies to environmental and user variations is tested using Monte-Carlo techniques. Under the conditions that were applied, reductions on the ventilation heat loss of 25 to $60 \%$ are found, depending on the chosen control strategy (with the exclusion of adventitious ventilation and infiltration).

\section{INTRODUCTION}

Advances in several disciplines of knowledge such as the growing understanding of global warming (IPCC, 2007) and its effects on our environment, the increasing evidence of the limited nature of our major energy supply and the large cost, both economical and human, of air pollution related illnesses are dramatically altering the goals of innovations in building technology. The focus is shifted towards 'green' or sustainable buildings, seeking concepts that allow to maintain or even further increase the comfort level that we are accustomed to, while significantly reducing the associated energy use in every aspect of human life.

In a moderate climate, hygiene ventilation is responsible for about half or more of the energy expenditure in well insulated dwellings, while the energy use in buildings itself takes up about $40 \%$ of the energy use in the EU. Consequently, this field represents a massive gross energy saving potential. Simply reducing ventilation rates, however, will deteriorate the indoor air quality and therefore sort unwanted effects such as an increase in the incidence of respiratory illness [1,2] and loss of productivity [3].

Two main strategies exist in contemporary building practice that allow to reconcile these opposing interests, namely the use of heat recovery units and the implementation of demand controlled ventilation. Heat recovery ventilation is widely spread in cold climates and its merits are discussed extensively in literature (eg. [4]).

However, in the moderate climate zone of western Europe, especially in the Netherlands, France, the UK and Belgium, with about 2500-3000 heating degree days [5, 6], the payback time for investments in heat recovery ventilation are long, especially in buildings with relatively low air change rates such as dwellings. Due to its competitive price setting as well as due to reports in popular media and scientific literature about possible health risks associated with heat recovery systems [7] simple mechanical exhaust ventilation dominates the residential ventilation market $[8,9]$ in this region. In light of this exhaust ventilation tradition, 
home owners tend to prefer demand controlled exhaust ventilation over heat recovery systems to comply with tightening energy performance legislation. However, little information is available in literature on the performance that can be achieved with different approaches to demand controlled exhaust ventilation. This paper presents performance and sensitivity results that can be used to understand and design appropriate residential demand controlled exhaust ventilation.

\subsection{Background}

Available literature on demand controlled systems is mainly focussed on two aspects: single-zone, large air change rate situations [10-13] on one hand and on optimal set point or control algorithm development [14, 15] on the other. Although few papers focus on the residential context [16], time use reports indicating that $70 \%$ of our time is spent at home and 50\% of that time is spent alone [17] clearly show the potential for demand control in dwellings.

In contrast to the dedicated air handling systems for large spaces such as open plan offices, conference halls and theatres, fresh air supply and exhaust in residential ventilation are usually decoupled in space. Fresh air is introduced in the living room and bedrooms whereas polluted air is extracted from the dwelling in 'wet' spaces such as kitchen, toilet and bathroom. Transfer devices in doors allow air to flow from the dry spaces to the wet spaces through hallways and staircases. This particular configuration requires a performance assessment on a multi-zone (system) level in order to account for inter zone interaction.

In addition to that, the rating of the indoor environment is a complex, multi-layered problem [18]. The long list of indoor air quality performance indicators for residential ventilation systems proposed in the EN 15665 standard [19] clearly demonstrates that no consensus exists on how to rate ventilation system performance. Nonetheless, the choice of performance criterion has a large influence on assessment results [20].

Residential ventilation systems are usually bought as a complete package with a set of standard components and are therefore far less tailor made than large HVAC systems. In a competitive market, reliable performance assessment and evaluation of these ventilation systems is essential, although the operating conditions (building geometry, wind conditions) can vary largely between dwellings and occupancy is susceptible to change over the lifetime of an installation.

\subsection{Scope}

This paper focuses on the energy saving potential of four demand control strategies for mechanical exhaust ventilation in residences on a system level and with their repercussions on the indoor air quality to which the occupants of the dwellings are exposed. This is in accordance with the dominant market trend in the moderate climate zone of western Europe. The robustness of the performance of these control strategies is assessed by sensitivity analysis based on Monte-Carlo techniques.

\section{MODELING}

The results presented in this paper are based on airflow simulations. These were executed in the multi-zone airflow simulation package Contam [21]. The validation of multi-zone ventilation models against e.g. tracer gas measurements is well documented in literature [22-25]. Multi-zone simulation models typically assume well mixed air in every room (simulated as a single node in the model). As a result, these models are not suited for detailed analysis of the distribution of contaminants in a single room. However, this is not the scope of this paper. In contrast to a typical office setting, no specific occupied zone can be defined in a residential setting. To assess the energy use related to hygiene ventilation, only the bulk fresh airflow in the building is relevant. As Contam is a ventilation model only, it cannot calculate transient room or duct temperatures. Therefore, for simplicity, the temperature inside the building and all ducts has been set to $18{ }^{\circ} \mathrm{C}$, the inside temperature fixed by the Belgian EPBD calculation procedure, which corresponds to the average temperature measured in Belgian dwellings [26]. The effect of this assumption has been discussed by Steeman [27]. In this section, the implementation of the building geometry in the model will be discussed first, followed by an overview of the used performance assessment parameters. Finally the selected demand control strategies will be presented.

\subsection{Building model}

The geometry used in the model is based on a detached house that is statistically representative for the average Belgian dwelling. It has been designed for and used in several previous research projects [28-32] and is 
currently used to assess the performance of residential ventilation systems in the EPBD framework in Belgium [33]. Table 1. lists the dimensions $\left(\mathrm{m}^{2}\right)$ of the spaces in the building model. Figures $1 \mathrm{a}$ and $1 \mathrm{~b}$ show the plan of the ground floor and $1^{\text {st }}$ floor of the dwelling, respectively.

The airflow in this dwelling has been modelled through the introduction of system components and leakage.

Overall airtightness, characterized by the $\mathrm{v}_{50}$ value, is modelled by means of cracks in the roof and wall surface. The $v_{50}$ value is the ratio of the air leakage rate at $50 \mathrm{~Pa}$ pressure difference and the building envelope heat loss area. According to observations by Bossaer [26], the specific leakage rate through roof and walls has a $2 / 3$ ratio, which has been implemented in the model. Each wall is fitted with two cracks, one at $1 / 4$ of its height and the second one at 3/4. The internal doors are simulated with additional cracks in the walls. For the indoor walls, a fixed specific leakage value is assumed. This methodology is in agreement with guidelines given in EN 15242 [34]. In the results presented, a specific airleakage ( $\left.\mathrm{v}_{50}\right)$ of $3 \mathrm{~m} / \mathrm{h}$ is used, representing the best quartile of measured airtightness values in a measurement campaign in Flanders in the late 90's [26]. A recent measurement campaign [35], along with results from other countries [36], shows a tendency towards this level of airtightness in newly built dwellings.

A mechanical exhaust ventilation system is implemented according to the requirements of the Belgian residential ventilation standard [37]. This standard imposes design flow rates for the main system components in an exhaust system. In general, the required flow rates are $3.6 \mathrm{~m} 3 / \mathrm{h} / \mathrm{m}^{2}$ of floor area, with minimum values for wet spaces such as kitchen and bathrooms. The resulting design flow rates are also listed in Table 1. The non-mechanically driven components (supply and internal transfer) are sized to supply the design flow rate at a $2 \mathrm{~Pa}$ pressure difference, in accordance with the standard. They are modelled to represent self regulating trickle ventilators [38] of the P3 class as defined in the Flemisch EPB-decree, according to the EN 13141-1 standard [39]. P3 class means that for pressure differences above $2 \mathrm{~Pa}$ the flow rate through the trickle ventilators levels off to a constant value, equal to the design flow rate, within certain margins [40] eg. 1.5 times the design flow rate in the 2-50 Pa range. This upper limit is used in the calculations [33].

\subsection{Assessment parameters}

Three parameters are used to assess the performance of the selected control strategies. Two of them concern indoor air quality, whereas the $3^{\text {rd }}$ deals with the energy saving potential. For the assessment of the level of indoor air quality the occupants are exposed to, the exposure to excess carbon dioxide concentration is used along with the exposure to a tracer gas.

Through the correlation between excess $\mathrm{CO}_{2}$ concentration and mean percentage of dissatisfied [41] and Fanger's Perceived Air Quality approach [42], excess $\mathrm{CO}_{2}$ concentration is now widely accepted as a proxy for perceived indoor air quality [43], especially if the main pollution sources are related to the human metabolism. In this paper, the mean excess $\mathrm{CO}_{2}$ concentration to which an occupant is exposed during his time of residence in the dwelling over the course of the heating season is used as a performance indicator. From all performance criteria proposed in EN 15665 [19] and in literature [44-48], this one is assumed to be best fit to represent the ability of the system to dilute occupant related pollutants for comparison to other systems. The production of $\mathrm{CO}_{2}$ within the model is only related to the occupants' metabolism and corresponds to their whereabouts. The production rate is, in accordance with EN 15251 [49], fixed at 19 1/h for an adult performing light work and $12 \mathrm{l} / \mathrm{h}$ for an adult at rest. A background outdoor concentration of 350 ppm is assumed.

In dwellings, however, non-metabolism related pollution sources are present in the sanitary units such as toilets and bathrooms. Consequently, the mean exposure to a tracer gas with sources in these specific rooms only is used to assess the efficiency of the ventilation system in removing this specific type of pollutants. The simulated tracer source is active every time an occupant is present in the toilet or bathroom, for the first 5 minutes of occupancy and at a fixed rate.

Exposure to emissions originating from building materials and their secondary effects can be reduced effectively with source control measures $[50,51]$. Therefore, it is not considered as a performance indicator for the ventilation systems in this paper.

As a measure for the energy saving potential of the demand controlled configurations, the total, heating season averaged, convective heat loss through ventilation for each demand controlled configurations is compared to that of the reference case with continuous flow rates. The latter is a reference for the achievable air quality with this kind of system [32]. Fan power was not taken into account because it is very system specific. 


\subsection{Demand control}

Four different demand control strategies were implemented on the basic exhaust ventilation system that is described in section 2.1. All of the strategies reduce the flow rates when ventilation need is limited in terms of perceived indoor air quality, relative humidity or presence of occupants. Three of those interact with a single system component (trickle ventilator, vent hole and fan), whereas the $4^{\text {th }}$ interacts with these system components simultaneously. All strategies are abstractions of commercially available systems. Table 2 . lists a summary of all strategies.

The first control strategy interacts with an economiser in the vent hole of each 'wet' room (kitchen, toilet, service room and bathroom) and is based on the relative humidity measured in the extracted air. A minimal flow rate of $10 \%$ of the design flow rate for each vent hole is maintained at all times. The flow through the vent hole is increased to the design flow rate if the measured relative humidity is higher than $70 \%$ and is reduced to the minimal flow rate again when it drops below $65 \%$. Note that the fan is not directly affected by this control strategy. The $70 \%$ setpoint is chosen because it is a marker for elevated mould risk on typical thermal bridges [52, 53]. An EMPD model [54] is used to simulate moisture buffering in the spaces.

The second strategy interacts only on the exhaust fan and is triggered by presence in either bathroom, toilet or kitchen. The total exhaust flow rate is reduced to $10 \%$ of the design flow rate after 20 minutes of absence in all of these rooms. With the detection of presence in any of these rooms, the exhaust flow rate is increased to the total design flow rate for exhaust again.

The third strategy interacts with the trickle ventilators (supply) and reduces their opening size according to the $\mathrm{CO}_{2}$ concentration in the room where the trickle ventilator is situated. If the $\mathrm{CO}_{2}$ concentration is below the setpoint of $1000 \mathrm{ppm}$, the opening size is reduced to $10 \%$ of the original size. The $1000 \mathrm{ppm}$ setpoint is popular value in demand control systems on the market [55]. It also corresponds quite well with the concentration that can be expected when an airflow rate of $36 \mathrm{~m}^{3} / \mathrm{h}$ of fresh air is provided for every occupant in a room, corresponding to the upper limit of the IDA 2 in EN 13779 [43], which is the basis of the design flow rates imposed in the Belgian standard. In this case, extraction flow rates are constant.

The last strategy interacts with all of the components manipulated in the first 3 strategies. The trickle ventilators are manipulated according to the $\mathrm{CO}_{2}$ concentration in the same way as is used in the third strategy. The vent holes and the exhaust ventilator are manipulated according to presence like in the second strategy.

\section{MONTE CARLO}

\subsection{Sensitivity}

The energy saving potential of a demand controlled ventilation system will be different for each building. In addition, one of the main problems with simulation models is the uncertainty on input data, despite the fact that the sensitivity of the results to variation in the input data may be very high. A lot of variables have a distinct influence on the performance of the system and consequently the performance of the system will be different for each set of parameters. Bearing that knowledge in mind one has to use a calculation method that takes both the variation of the different parameters as well as the interaction between them into account in order to acquire statistically relevant data. Large sensitivity to input uncertainty often appears near equilibrium situations which occur for specific values of structural parameters or weather conditions [56, 57].

To prevent this input dependency of the results, the Monte-Carlo (MC) approach, as proposed by Van Den Bossche et al. [33], has been used in this study. In this approach, instead of fixing 1 value for each input data, a distribution is determined for the key parameters and multiple simulations are carried out with different values of these parameters. According to Furbringer [56, 57] convergence can be reached within 100 simulations if the amount of input parameters is limited.

Sensitivity analysis based on a Monte Carlo algorithm has been implemented in building simulation by e.g. Breesch [58]. Dorer et al. [59,60] presented work specifically for residential ventilation systems within the framework of the EC Reshyvent - EU cluster project.

The Monte-Carlo process can be speeded up by using Low Discrepancy Sequences (LDS) instead of random numbers [61]. In contrast to randomly sampled points, they distribute the instances to empty areas in the sample space to prevent overlapping and clusters, which are very common with ordinary random numbers. Another advantage of LDS is that these sequences are entirely repeatable, giving the same sequence every time. These sequences are used to generate the parameter sets used in this paper. 


\subsection{Implementation of stochastic analysis}

A sensivity analysis has pointed out that the building airtightness, wind related factors such as wind velocity and wind reduction parameters [62] and the number of inhabitants and their occupancy schedules have the biggest influence on the overall performance of the ventilation system [33].

The following input variables are considered with a probabilistic approach (Normal distributions are mentioned as $\mathrm{N}$ (mean, standard deviation):

- Façade orientation - interval $\left[0^{\circ} ; 359^{\circ}\right]$

- $\quad \mathrm{C}_{\mathrm{p}}$ coefficients - interval of the 6 AIVC tables [63]

- $\quad$ Terrain roughness $\alpha$, partially correlated with the $C_{p}$ coefficients - interval [0.149 - 0.377]

- $\quad$ Length of the ducts in the attic - N(6,5m, 1,5m)

- $\quad$ Airtightness of the ducts - N(0,0675 1/s/m², 0,027 1/s/m²)

- Sunday is the ... ${ }^{\text {th }}$ day of the year - interval [1;7]

- Moisture production from domestic activities - normal distribution (see below)

- Production of moisture and carbon dioxide by occupants - normal distribution (see below)

- Number of occupants - specific distribution

- Weekday / weekend occupancy schedules - specific distribution

The number of parameters can be considered to be small, so 100 datasets will be used to perform the simulations. Moisture production for domestic activities is based on data available in the EU technical report on design and dimensioning of residential ventilation systems [64]. The production in the bathroom is $\mathrm{N}[0.5$, $0.05) \mathrm{l} / \mathrm{s}$, in the service room cloth drying is $\mathrm{N}(1,0.05) \mathrm{l} / \mathrm{s}$ and for cooking, a half hour cycle of $\mathrm{N}(0.6,0.05) \mathrm{l} / \mathrm{s}$, $\mathrm{N}(1,0.1) \mathrm{l} / \mathrm{s}$ and $\mathrm{N}(1.5,0.1) \mathrm{l} / \mathrm{s}$ for 10 minutes each is used. The production of moisture and carbon dioxide by occupants is modelled as a linear function of the metabolism, which varies for each activity $(\mathrm{eg} . \mathrm{N}(0.8,0.05)$ met for sleeping, $\mathrm{N}(2,0.1)$ met for cooking). Based on EN 15251[49], the production rate is $11.8751 / \mathrm{h} / \mathrm{met}$ for $\mathrm{CO}_{2}$ and $34.375 \mathrm{~g} / \mathrm{h} / \mathrm{met}$ for moisture. The number of occupants and the occupancy schedules are considered with a specific distribution based on the social demography and time use studies in Belgium. Based on the available data, 100 different data sets were compiled with different occupancy schedules. The number of occupants in the building varies from one to six $(1: 3 \%, 2: 21 \%, 3: 31 \%, 4: 32 \%, 5: 10 \%, 6: 3 \%)$, with an average of 3.34 persons per building. Figure 2. shows the probability that at least one person is present in a room over the course of a weekday.

\section{RESULTS \& DISCUSSION}

As was detailed in section 3.2, 100 simulations were carried out for each of the strategies that was discussed in section 2.3 In this section, the results of these simulations will be presented.

All simulations were run over the heating season only, in this case between September $28^{\text {th }}$ and April $15^{\text {th }}$, using the Test Reference Year for Ukkel climate data [65]. In section 2.2, three assessment parameters were proposed. Figures 3, 4 and 5 show the distribution of the results for the energy indicator (average heat loss, $\mathrm{kW}$ ), the perceived indoor air quality indicator (average excess $\mathrm{CO}_{2}$-concentration) and the extraction efficiency indicator (mean exposure, $\mathrm{g} / \mathrm{kg}$ ), respectively, for each of the 4 demand control strategies. Additionally, the results for the standard exhaust system are included in the figures as a reference.

\subsection{Energy saving potential}

As can be seen in Figure 3, the control strategies that only control the exhaust air flow, either trough manipulation of the vent hole (Crh) or by manipulation of the exhaust fan (Cpres), have about the same energy saving potential. However, in comparison with the base case with constant flow exhaust ventilation, the heat loss is slightly more sensitive to changes in the environmental parameters. The control strategy where the trickle ventilators are manipulated (Cco2) has a comparable average saving potential as the first two strategies, but in contrast to them, makes the heat loss associated with ventilation much more robust, which can be observed in the much steeper curve in Figure 3.

This can be explained by the flow dynamics in the dwelling. Two driving forces determine the flow pattern through the model: mechanically induced forced ventilation flow on one hand, climate induced flow caused by the buoyancy effect and wind pressure $[66,67]$ on the other. While the mechanical flow is constant and well controlled, the climate induced flow is governed by fluctuating environmental parameters and therefore more variable. The control strategies that reduce or manipulate the exhaust flow will reduce the proportional influence of the mechanical flow and their performance will therefore be more sensitive to changes in environmental parameters. By manipulating the trickle ventilators, however, the natural convection 
component is reduced and the under pressure created by the mechanical exhaust is increased, considerably increasing the proportional influence of the forced flow and reducing the sensitivity to environmental parameters.

Since the $4^{\text {th }}$ strategy reduces both the mechanical exhaust and the opening size of the trickle ventilators (Call), the heat loss results for this configuration have about the same robustness as the base case.

This effect is also visible in Figure 6, where the results for the energy indicator are shown for simulations with the $1^{\text {st }}$ data set of the Monte Carlo algorithm for different levels of airtightness. In this set, all parameters are set to their average value. While all other strategies, like the base case, are linearly proportional to the airtightness level, the strategy that manipulates the trickle ventilators levels off to a constant performance in the more airtight range. Note that the projected intersection of the curves with the Y-axis in figure 6 defines the ventilation heat loss in absence of infiltration and adventitious ventilation.

\subsection{Indoor air quality}

From Figure 4. we can conclude that both the control strategy based on presence detection and the one based on $\mathrm{CO}_{2}$ detection render a perceived indoor air quality level that is comparable to that of the original constant flow system. The $\mathrm{CO}_{2}$ based strategy is slightly more robust, as was explained in the previous section. The control strategy based on relative humidity has a negative impact on the perceived indoor air quality level and increases the sensitivity. This can be explained by the fact that relative humidity is influenced by a lot of factors, such as hygroscopic buffering, ventilation rate, and outdoor climate, whereas the performance criterion, exposure to $\mathrm{CO}_{2}$, is only function of occupancy.

The control strategy with simultaneous manipulation of the trickle ventilators, vent holes and exhaust fan considerably increases the mean exposure to $\mathrm{CO}_{2}$ compared to the base case. When, instead of the distribution of the mean exposure (as in Figure 4.) the distribution of all instantaneous concentrations, to which the occupants are exposed in the simulations, are plotted, however, like in Figure 7, we can see that the increased mean exposure is mainly due to an increase in exposure to concentrations below $600 \mathrm{ppm}$ above the outdoor concentration, while the increase in exposure to higher concentrations is negligible. Since the EN 13779 standard [43] considers concentrations below $600 \mathrm{ppm}$ above outdoor concentration to indicate good indoor air quality (IDA II), the increased exposure in the $4^{\text {th }}$ control strategy is still acceptable. Note that the $\mathrm{CO}_{2}$ based strategy, with constant exhaust rates, drastically reduces exposure to high concentrations.

The results for extraction efficiency of the tracer gas in the wet spaces (Figure 5) are similar to those for perceived indoor air quality. Again, the control strategy based on relative humidity results in a less efficient system because of the intricate relation between elevated relative humidity and ventilation demand. The combined control strategy now produces results in the same range as the constant flow base case and the presence and $\mathrm{CO}_{2}$ based control strategies.

Table 3. shows the results for the indicators based on a single simulation where all parameters from the Monte Carlo algorithm are set to their average value. These results are compared to the median value of the Monte Carlo results Although a lot of information is lost when only one simulation is done, the results prove to be a good estimate for the relative performance of the control strategy on all indicators. For the energy and perceived indoor air quality indicator, they even coincide well with the average results of the Monte Carlo analysis.

\section{CONCLUSIONS}

In this paper, the energy saving potential and the repercussions on the indoor air quality of 4 different demand control strategies for residential ventilation were investigated. Two performance indicators were proposed to assess the indoor air quality, one dealing with perceived indoor air quality and one dealing with the efficiency of extraction of specific pollution from 'wet' areas in the dwelling. Monte Carlo analysis was used to assess the sensitivity of the control strategies to changes in occupancy, environmental boundary conditions and dimensional parameters.

The 3 demand control strategies that only manipulate 1 system component rendered an energy saving potential of about $25 \%$, whereas the strategy with combined manipulation of supply, vent and exhaust fan had an energy saving potential of $60 \%$. Strategies that manipulate supply proved to be more robust, with performances that are less sensitive to variable conditions such as climate and occupancy.

The control strategy based on relative humidity was least suited to maintain the indoor air quality at the level of the base case with constant exhaust flow, although the indoor air quality level was within the same range for all of the proposed strategies. Only for the combined strategy the perceived indoor air quality seemed significantly worse than in the base case. Further analysis, however, revealed that the exposure to 
elevated carbon dioxide levels was comparable to that of the other strategies. The strategy that manipulates the trickle ventilators proved to drastically reduce peak exposure to metabolism related pollutants.

The results obtained with a single simulation with average input values proved to be a good indicator for the relative performance of a control strategy although they do not provide any information on sensitivity. They can therefore be useful in optimization exercises, but in an overall assessment of a new control strategy, sensitivity analysis should be included.

\section{REFERENCES}

[1] Seppanen OA, Fisk WJ. Summary of human responses to ventilation. Indoor Air. 2004;14:102-18.

[2] Kovesi T, Zaloum C, Stocco C, Fugler D, Dales RE, Ni A, et al. Heat recovery ventilators prevent respiratory disorders in Inuit children. Indoor Air. 2009;19:489-99.

[3] Wargocki P, Lagercrantz L, Witterseh T, Sundell J, Wyon DP, Fanger PO. Subjective perceptions, symptom intensity and performance: a comparison of two independent studies, both changing similarly the pollution load in an office. Indoor Air. 2002;12:7480.

[4] Juodis E. Extracted ventilation air heat recovery efficiency as a function of a building's thermal properties. Energy and Buildings. 2006;38:568-73.

[5] Eurostat. Heating degree-days - annual data. 18-02-2010 ed2010.

[6] ISO. Hygrothermal performance of buildings - Calculation and presentation of climatic data - Part 6: Accumulated temperature differences (degree-days). Geneva2007.

[7] Meijer A, Verkade A-J, Merckx A-M, Duijm F, Bolscher GHt. The effects of improvement measures for ventilation on the indoor environment and health complaints in Vathorst. Clima 2010. Antalya2010.

[8] De Gids W. Ventilation in Dutch houses - a study in a representative sample of the dutch housing stock. 24th AIVC conference: ventilation, humidity control \& energy. Washington DC: AIVC; 2003.

[9] Durier F. Trends in the French building ventilation market and drivers for changes. In: AIVC, editor. Ventilation Information Papers2008.

[10] Fisk WJ, De Almeida AT. Sensor-based demand-controlled ventilation: a review. Energy and Buildings. 1998;29:35-45.

[11] Chao CYH, Hu JS. Development of a dual-mode demand control ventilation strategy for indoor air quality control and energy saving. Building and Environment. 2004;39:385-97.

[12] Zhou L, Haghighat F. Optimization of ventilation system design and operation in office environment, Part I: Methodology.

Building and Environment. 2009;44:651-6.

[13] Zhou L, Haghighat F. Optimization of ventilation systems in office environment, Part II: Results and discussions. Building and Environment. 2009;44:657-65.

[14] Wang SW, Xu XH. Optimal and robust control of outdoor ventilation airflow rate for improving energy efficiency and IAQ. Building and Environment. 2004;39:763-73.

[15] Mui KW, Chan WT. Building calibration for IAQ management. Building and Environment. 2006;41:877-86.

[16] Pavlovas V. Demand controlled ventilation - A case study for existing Swedish multifamily buildings. Energy and Buildings. 2004;36:1029-34.

[17] Glorieux IM, J. Belgisch tijdsbudgetonderzoek. Brussels2008.

[18] Bluyssen PM. Towards an integrative approach of improving indoor air quality. Building and Environment. 2009;44:1980-9.

[19] CEN. Ventilation in buildings - Determining performance criteria for design of residential ventlilation systems. Brussels2009.

[20] Laverge J, Janssens A. Comparison of code-compliant residential ventilation systems on a performance basis. Building Physics Symposium in honour of Prof HLSC Hens. Leuven2008.

[21] Dols WS. A tool for modeling airflow \& contaminant transport. Ashrae Journal. 2001;43:35-+.

[22] Emmerich SJ. Validation of multizone IAQ modeling of residential-scale buildings: a review. ASHRAE Transactions. Cincinnati: ASHRAE; 2001. p. 619-28.

[23] Emmerich SJ. Validation of contamw predictions for tracer gas in a townhouse. In: IBPSA, editor. 8th international IBPSA conference. Eindhoven: IBPSA; 2003. p. 299-306.

[24] Delsante A, Aggerholm S. The use of simulation tools to evaluate hybrid ventilation control strategies. Annex 35 technical report: IEA/ECBCS; 2002.

[25] Bossaer A, Wouters P, Ducarme D. Evaluation of COMIS 1.2 by whole model validation: A case study. Indoor Air Quality, Ventilation and Energy Conservation in Buildings, Vols 1 and 2. 1995:369-76.

[26] Bossaer A, Demeester J, Wouters P, Vandermarke B, Vangroenweghe W. Airtightness performances in new Belgian dwellings. 19th AIVC conference: ventilation technologies in urban areas. 19 ed. Oslo: AIVC; 1998. p. 77-84.

[27] Steeman M. On modelling moisture buffering when evaluating humidity controlled hvac systems. Building Simulation 2009. Glasgow2009. p. 819-26.

[28] Verbeeck G. Life cycle optimization of extremely low energy dwellings. J Build Phys. 2007;31:143-77.

[29] Verbeeck G, Hens H. Energy savings in retrofitted dwellings: economically viable? Energy and Buildings. 2005;37:747-54.

[30] Verbeeck G, Hens H. Life cycle inventory of buildings: A calculation method. Building and Environment.45:1037-41.

[31] Verbeeck G, Hens H. Life cycle inventory of buildings: A contribution analysis. Building and Environment.45:964-7.

[32] Janssens A, Willems L, Laverge J. Performance evaluation of residential ventilation systems based on multi-zone ventilation models. International Building Physics Conference. Istanbul2008. 
[33] Van Den Bossche N, Janssens A, Heijmans N, Wouters P. Performance evaluation of humidity controlled ventilation strategies in residential buildings. Thermal performance of the exterior envelopes of whole buildings X. Clearwater2007. p. 7.

[34] CEN. Ventilation for buildings - Calculation methods for the determination of air flow rates in buildings including infiltration. Brussels2007.

[35] Laverge J, Vandevelde S, Debrauwere T, Delghust M, Janssens A. Airtightness assessment of newly build single family houses in Belgium. Buildair 2010. Copenhagen2010.

[36] Pan W. Relationships between air-tightness and its influencing factors of post-2006 new-build dwellings in the UK. Building and Environment.45:2387-99.

[37] BIN. Ventilatievoorzieningen in woongebouwen. Brussels1991.

[38] Karava P, Stathopoulos T, Athienitis AK. Investigation of the performance of trickle ventilators. Building and Environment. 2003;38:981-93.

[39] CEN. Ventilation for buildings - Performance testing of components/products for residential ventilation - part. 1: extarnally and internally mounted air transfer devices. Brussels2004.

[40] Willems L, Janssens A. Performance prediction of dwelling ventilation with self-regulating air inlets. 26th AIVC conference: ventilation in relation to the engery performance of buildings. 26th ed. Brussels: AIVC; 2005. p. 197-202.

[41] CEN. Ventilation for buildings - Design criteria for the indoor environment. Brussels1998.

[42] Fanger PO. Introduction of the olf and decipol unit to quantify air-pollution perceived by humans indoors and outdoors. Energy and Buildings. 1988;12:1-6.

[43] CEN. Ventilation for non-residential builidings - performance requirements for ventilation and room-conditioning systems. Brussels2004.

[44] Jokl MV. Evaluation of indoor air quality using the decibel concept based on carbon dioxide and TVOC. Building and Environment. 2000;35:677-97.

[45] Mui KW, Wong LT, Ho WL. Evaluation on sampling point densities for assessing indoor air quality. Building and Environment. 2006;41:1515-21.

[46] Wong LT, Mui KW. Evaluation on four sampling schemes for assessing indoor air quality. Building and Environment. 2007;42:1119-25.

[47] Wong LT, Mui KW, Hui PS. A statistical model for characterizing common air pollutants in air-conditioned offices. Atmospheric Environment. 2006;40:4246-57.

[48] Zhu CH, Li NP, Re D, Guan J. Uncertainty in indoor air quality and grey system method. Building and Environment. 2007;42:1711-7.

[49] CEN. Criteria for the indoor environment, inluding thermal, indor air quality, light and noise. Brussels2005.

[50] Knudsen HN, Wargocki P. Strategy for good perceived air quality in sustainable buildings. Clima 2010. Antalya2010.

[51] Kurnitski J, Seppanen OA. Trends and drivers in the Finnisch ventilation and AC market. In: AIVC, editor. Ventilation Information Papers. Brussels: AIVC; 2008.

[52] Viitanen H, Vinha J, Salminen K, Ojanen T, Peuhkuri R, Paajanen L, et al. Moisture and Bio-deterioration Risk of Building Materials and Structures. J Build Phys.33:201-24.

[53] Isaksson T, Thelandersson S, Ekstrand-Tobin A, Johansson P. Critical conditions for onset of mould growth under varying climate conditions. Building and Environment.45:1712-21.

[54] Janssen H, Roels S. Qualitative and quantitative assessment of interior moisture buffering by enclosures. Energy and Buildings. 2009;41:382-94.

[55] Nielsen TR, Drivsholm C. Energy efficient demand controlled ventilation in single family houses. Energy and Buildings.42:1995-8.

[56] Furbringer JM, Roulet CA. Confidence of simulation results: put a sensitivity analysis module in your MODEL - The IEAECBCS Annex 23 experience of model evaluation. Energy and Buildings. 1999;30:61-71.

[57] Furbringer JM, Roulet CA. Comparison and combination of factorial and Monte-Carlo design in sensitivity analysis. Building and Environment. 1995;30:505-19.

[58] Breesch H, Janssens A. Performance evaluation of passive cooling in office buildings based on uncertainty and sensitivity analysis. Sol Energy. 2010;84:1453-67.

[59] Dorer V, Pfeiffer A, Weber A. Parameters for the design of demand controlled hybrid ventilation systems for residential buildings. AIVC Technical Notes. Brussels: AIVC; 2005. p. 120.

[60] Pfeiffer A, Dorer V, Weber A. Modelling of cowl performance in building simulation tools using experimental data and computational fluid dynamics. Building and Environment. 2008;43:1361-72.

[61] Winiarski M. Quasi-Monte Carlo dervative valuation and reduction of simulation bias. Stockholm: Royal Institute of Technology; 2003.

[62] Costola D, Blocken B, Hensen JLM. Overview of pressure coefficient data in building energy simulation and airflow network programs. Building and Environment. 2009;44:2027-36.

[63] Liddament MW. A guide to energy efficient ventilation. AIVC Guides. Brussels: AIVC; 1996.

[64] CEN. Ventilation for buildings - Design and dimensioning of residential ventilation systems. Brussels2005.

[65] ISO. Hygrothermal performance of buildings - Calculation and presentaion of climatic data - Part 4: Hourly data for assessing the annual energy use for heating and cooling. Geneva2005.

[66] Andersen KT. Airflow rates by combined natural ventilation with opposing wind-unambiguous solutions for practical use.

Building and Environment. 2007;42:534-42.

[67] Andersen KT. Theory for natural ventilation by thermal buoyancy in one zone with uniform temperature. Building and Environment. 2003;38:1281-9. 
List of figures:

Figures 1a, b. Ground floor (above) and fist floor (below) of the simulated building.

Figure 2. Probability that at least one person is present in a room over the course of a weekday.

Figure 3. Distribution of the mean heat loss $(\mathrm{kW})$ associated with fresh air supply to the dwelling of the 100 cases selected in the Monte Carlo analysis for the base case (exhaust ventilation) and the 4 selected demand control strategies.

Figure 4. Distribution of the mean exposure to excess $\mathrm{CO}_{2}$ concentration (ppm above the outdoor concentration) of the 334 occupants in the 100 cases selected in the Monte Carlo analysis for the base case (exhaust ventilation) and the 4 selected demand control strategies.

Figures 5. Distribution of the mean exposure to the tracer gas $(\mathrm{kg} / \mathrm{kg})$ of the 334 occupants in the 100 cases selected in the Monte Carlo analysis for the base case (exhaust ventilation) and the 4 selected demand control strategies.

Figures 6. Mean total energy loss $(\mathrm{kW})$ associated with fresh air supply to the dwelling at different airtightness levels (v50) for the base case (exhaust ventilation) and the 4 selected demand control strategies.

Figures 7. Distribution of exposure of all the occupants to $\mathrm{CO}_{2}$ concentrations above outdoor concentration (ppm) for the base case (exhaust ventilation) and the 4 selected demand control strategies.

List of tables:

Table 1. floor area $\left(\mathrm{m}^{2}\right)$ and design supply / extraction airflow rate $\left(\mathrm{m}^{3} / \mathrm{h}\right)$ of the spaces in the building model

Table 2. selected demand control strategies

Table 3. single simulation results (a) - median of monte-carlo results (b) 